\title{
Oral mucosal alterations among the institutionalized elderly in Brazil
}

\section{Raquel Conceição Ferreira(a) Cláudia Silami de Magalhães ${ }^{(b)}$ Allyson Nogueira Moreira ${ }^{(b)}$}

\footnotetext{
(a) Doctor of Dental Science, Department of Dentistry, State University of Montes Claros, Montes Claros, Minas Gerais, Brazil.

(b) Doctor of Dental Science, Department of Restorative Dentistry, Dental School, Federal University of Minas Gerais, Belo Horizonte, Minas Gerais, Brazil.
}

\begin{abstract}
This study determined the prevalence of oral mucosal alterations and associated factors among the institutionalized elderly in Brazil. Data were collected through a structured questionnaire, a review of their medical records and an intra-oral examination. A sample of 335 individuals over 60 years of age was randomly selected. In total, 646 alterations were diagnosed; $59.1 \%$ were variations of the normal oral mucosa. The most frequent variation consisted of sublingual varicosities $(51.6 \%)$. Denture stomatitis $(15.2 \%)$ and denture hyperplasia $(12.8 \%)$ were the most frequent lesions. Elderly patients who wore dentures had a significantly higher prevalence of oral mucosal lesions $(\mathrm{p}=0.00)$ than those that didn't wear dentures. There was a high prevalence of variations of the normal oral mucosa and of mucosal lesions, especially denture-induced lesions, among the institutionalized elderly.
\end{abstract}

Descriptors: Mouth mucosa; Aging; Nursing homes; Dental prosthesis.

\section{Introduction}

There is a growing interest in the oral health status of the elderly, as the size of this population is increasing worldwide. In dentistry, there is an increasing emphasis on maintaining oral health into the old age, when alterations in oral tissues are associated with various conditions. ${ }^{1}$

Although the prevalence of oral mucosal disease has been found to be higher in older subjects, age is not considered to be the only factor correlated with oral mucosal disorders. Other factors, such as trauma, systemic diseases, the presence of medications and oral and denture hygiene, may also influence the development of oral mucosal diseases. ${ }^{2}$ The investigation of denture-induced lesions in the elderly Brazilian population is important because this age stratum had a high prevalence of edentulousness as a result of the precariousness of the government's provision of services, the predominance pattern of the curative oral health care, largely within the private practice domain, coupled to an extremely unreliable intervention of the State over time. ${ }^{3}$

Epidemiologic prevalence studies primarily "describe the amount of disorder existing in a population at a particular time". ${ }^{4}$ Basic information of this kind can "provide guidance in the administration of health services; it may be used to explain local disease occurrence and eventually contribute toward the understanding of the natural history of a disease". ${ }^{4}$

The prevalence of oral mucosal alterations among the institutionalized elderly was previously demonstrated mainly by international studies. ${ }^{5-9}$ In
Received for publication on Feb 09, 2010 Accepted for publication on May 24, 2010

\section{Corresponding author: \\ Universidade Estadual de Montes Claros, \\ Centro de Ciências Biológicas e da Saúde, \\ Av. Rui Braga S/N - Vila Maurć,ia \\ CEP: 39400-000 \\ E-mail: ferreirarc@hotmail.com}


Brazil, such data were obtained through a localized study involving a single institution ${ }^{8}$ or by recording the presence or absence of lesions. ${ }^{9}$ The present cross-sectional study investigated the prevalence of oral mucosal alterations and associated factors in a Brazilian institutionalized elderly population.

\section{Material and Methods}

The present cross-sectional study was conducted between November 2006 and June 2008.

\section{Sample}

The target population was composed of 1,669 individuals older than 60 years of age who were residents at 65 nursing homes distributed among 9 administrative districts in the city of Belo Horizonte, Brazil, 32 of which were philanthropic institutions and 33 of which were private institutions. Those who where terminally ill and individuals who did not permit the clinical examination or did not contribute to the interview due to aggression or behavioral alterations were excluded from the study. Individuals with cognitive impairment, as evaluated by the Mini-Mental Screening Exam, were also excluded if socio-demographic records were not available.

The sample size of 345 elderly was generated using the formula of estimation of proportions (prevalence $=50 \%$, sampling error $=5 \%$, confidence level $=95 \%$, significance $=5 \%$ ) after correction for a finite population and an increase of $10 \%$ to compensate for possible losses.

Sample selection was carried out using proportional, stratified, random samples, considering stratifications in the following order: modality of the institution, location of the institution in the administrative district of the city, and sex of the resident. The proportional size of each segment of the population was maintained in the sample. At each institution, the elderly were randomly selected by lot.

The ethics committee at the Federal University of Minas Gerais approved this research.

\section{Data collection}

The variables of age, sex, marital status, educational level and duration of institutionalization were collected through an interview and institutional and medical records. The examination was carried out by only one trained examiner, and the records were collected by an undergraduate dental student.

Denture wear was recorded according to the World Health Organization (WHO) guidelines. ${ }^{10}$ Soft tissue examination was undertaken using twoplane mouth-mirrors and gauze compresses under artificial light (a spotlight), with the elderly patients in portable dentist chairs, wheelchairs or in a bed. When present, a partial or full prostheses was removed before the examination. The diagnosis of oral mucosal alterations was made based on the clinical features according to the WHO. ${ }^{11}$ The Axéll definitions were used for alterations without published WHO diagnosis criteria., ${ }^{4,12}$ Additionally, a color atlas was used to aid in the positive identification of lesions during data collection. ${ }^{13}$ No biopsies, cytology or other tests were included in these results. Lesions were considered to be denture-related if they were situated on the oral mucosa covered by the removable prostheses and if there was no other obvious explanation.

In this study, a distinction was made between the oral conditions arising from pathologic processes with a specific etiology, treatment requirement or prognosis, which were classified as lesions, and conditions that, even with a well-established pathogenesis, presented no health impairment, required no treatment, and had been described in many texts as common and not hazardous to oral health. In the present study, such lesions were classified as variations of normal. Patients with oral mucosal lesions were referred to the dental school at the Federal University of Minas Gerais.

\section{Data analysis}

The data were submitted to a descriptive analysis. The association between the oral mucosal lesions and studied variables was tested by the chi-square test $(\mathrm{p}<0.05)$. SPSS v. 17 software (IBM Company, Chicago, Illinois, USA) was used.

\section{Results}

A total of 335 (97.1\%) elderly people participated. The reasons for the non-participation of 10 individuals included not wanting to be examined by an 
unfamiliar dentist (3), the perception of the study as unimportant (2), inconvenience (2) and not feeling well at the time of the investigation (3).

In total, 646 oral mucosal alterations were recorded in 267 (79.7\%) elderly people. However, 382 of these alterations $(59.1 \%)$ were considered varia- tions of normal mucosa. Twenty different diagnoses were found, and the most frequent were sublingual varicosities $(51.5 \%)$, coated tongue $(27.8 \%)$, Fordyce's spots (20.9), denture stomatitis $(15.2 \%)$ and denture hyperplasia (12.8\%) (Table 1).

Table 2 shows the characterization of the study

Table 1 - Prevalence of oral mucosal alterations among the institutionalized elderly. Belo Horizonte, Brazil, 2008.

\begin{tabular}{|c|c|c|c|}
\hline \multirow[b]{2}{*}{ Oral mucosal alterations } & \multicolumn{3}{|c|}{ Total } \\
\hline & $\mathrm{n}$ & $\%$ population & $\begin{array}{l}\% \text { total of } \\
\text { lesions }\end{array}$ \\
\hline \multicolumn{4}{|l|}{ Lesions } \\
\hline - Denture stomatitis & 51 & 15.2 & 7.9 \\
\hline - Denture hyperplasia & 43 & 12.8 & 6.7 \\
\hline - Flabby ridge & 31 & 9.3 & 4.8 \\
\hline - Denture-related ulcer & 25 & 7.5 & 3.9 \\
\hline - Frictional keratosis & 25 & 7.5 & 3.9 \\
\hline - Angular cheilitis & 19 & 5.7 & 2.9 \\
\hline $\begin{array}{l}\text { - Hyperplasia of the mucosa in a local corresponding } \\
\text { to a suction chamber of an upper denture }\end{array}$ & 11 & 3.3 & 1.7 \\
\hline - Leukoplakia & 11 & 3.3 & 1.7 \\
\hline - Acute pseudomembranous candidosis & 10 & 3.0 & 1.5 \\
\hline - Median rhomboid glossitis & 9 & 2.7 & 1.4 \\
\hline - Fibroma (fibroepithelial polyp) & 5 & 1.5 & 0.8 \\
\hline - Submucosal hemorrhage & 5 & 1.5 & 0.8 \\
\hline - Cheek and lip biting & 3 & 0.9 & 0.4 \\
\hline - Aphthous ulcer & 3 & 0.9 & 0.4 \\
\hline - Atrophy of tongue papillae, unspecified & 2 & 0.6 & 0.3 \\
\hline - Papilliform hyperplasia of palate & 2 & 0.6 & 0.3 \\
\hline - Erythroplakia & 2 & 0.6 & 0.3 \\
\hline - Traumatic ulcer (bite) & 2 & 0.6 & 0.3 \\
\hline - Mucocele & 2 & 0.6 & 0.3 \\
\hline - Lichen planus & 1 & 0.3 & 0.2 \\
\hline - Carcinoma & 1 & 0.3 & 0.2 \\
\hline - Cleft palate & 1 & 0.3 & 0.2 \\
\hline Total & 264 & & \\
\hline \multicolumn{4}{|l|}{ Variations of normal } \\
\hline - Sublingual varicosities & 173 & 51.6 & 26.8 \\
\hline - Coated tongue & 93 & 27.8 & 14.4 \\
\hline - Fordyce's spots & 70 & 20.9 & 10.8 \\
\hline - Piclated tongue & 22 & 6.6 & 3.4 \\
\hline - Torus palatinus & 11 & 3.3 & 1.7 \\
\hline - Excessive melanin pigmentation & 9 & 2.7 & 1.4 \\
\hline - Geographic tongue & 4 & 1.2 & 0.6 \\
\hline Total & 382 & & 100 \\
\hline
\end{tabular}


Table 2 - Distribution of the elderly in terms of age group, sex, marital status, education level, duration of institutionalization and denture wear and variation in the prevalence of oral mucosal lesions according to these variables. Belo Horizonte, Brazil, 2008.

\begin{tabular}{|c|c|c|c|c|}
\hline \multirow{2}{*}{ Variables } & \multirow{2}{*}{$\%(n=335)$} & \multicolumn{2}{|c|}{ Oral mucosal lesions } & \multirow{2}{*}{$\mathrm{p}$ value } \\
\hline & & Presence & Absence & \\
\hline \multicolumn{5}{|l|}{ Age group* } \\
\hline - 60 to 69 years & 15.9 & $24(14.6 \%)$ & 29 (17.1\%) & \multirow{3}{*}{0.62} \\
\hline - 70 to 79 years & 34.1 & $60(36.6 \%)$ & $54(31.8 \%)$ & \\
\hline$\cdot \geq 80$ years & 50.0 & $80(48.8 \%)$ & 87 (51.2\%) & \\
\hline \multicolumn{5}{|l|}{ Sex } \\
\hline - Male & 26.9 & $48(29.1 \%)$ & $42(24.7 \%)$ & \multirow{2}{*}{0.36} \\
\hline - Female & 73.1 & 117 (70.9\%) & $128(75.3 \%)$ & \\
\hline \multicolumn{5}{|l|}{ Marital status } \\
\hline - Single, widowed or divorced\# & 94.0 & $154(93.3 \%)$ & $161(94.7 \%)$ & \multirow{2}{*}{0.60} \\
\hline - Married & 6.0 & 11 (6.7\%) & $9 \quad(5.3 \%)$ & \\
\hline \multicolumn{5}{|l|}{ Education level: years of study } \\
\hline$\cdot 0$ & 27.2 & $39(23.6 \%)$ & $52(30.6 \%)$ & \multirow{5}{*}{0.06} \\
\hline - 1 to 4 & 43.6 & $83(50.3 \%)$ & $63(37.1 \%)$ & \\
\hline - 5 to 8 & 11.6 & $21(12.7 \%)$ & $18(10.6 \%)$ & \\
\hline - 9 to 11 & 13.7 & $17(10.3 \%)$ & 29 (17.1\%) & \\
\hline$\cdot \geq 12$ & 3.9 & $5 \quad(3 \%)$ & $8 \quad(4.7 \%)$ & \\
\hline \multicolumn{5}{|l|}{ Duration of institutionalization ${ }^{* *}$} \\
\hline - 0 to 5 years & 70.3 & $121(74.7 \%)$ & $109(66.1 \%)$ & \multirow{3}{*}{0.21} \\
\hline - 6 to 10 years & 14.4 & $21(13 \%)$ & $26(15.8 \%)$ & \\
\hline$\cdot \geq 10$ years & 15.3 & $20(12.3 \%)$ & $30(18.2 \%)$ & \\
\hline \multicolumn{5}{|l|}{ Removable prostheses wear } \\
\hline - Yes & 51.3 & 117 (70.9\%) & 55 (32.4\%) & \multirow{2}{*}{0.00} \\
\hline - No & 48.7 & $48(29.1 \%)$ & 115 (67.6\%) & \\
\hline
\end{tabular}

*Absence of records on the age of one elderly subject. ${ }^{* *}$ Eight institutions without entrance dates for the elderly patients. \#Single (40.9\%), widowed (43\%), and divorced (10.1\%).

population and the association between the oral mucosal lesions and the studied variables. Approximately half of the elderly wore removable prostheses that were partial or complete. Details on the prostheses worn by this population have been previously described. ${ }^{14}$ The prevalence of the oral mucosal lesions was significantly associated with removable prostheses wear (Table 2).

\section{Discussion}

Belo Horizonte has an elderly population estimated at approximately 204,573 individuals. ${ }^{15}$ At the time of the data collection, 1,669 of these elderly people resided in nursing homes. The evaluation of only the nursing home population did not affect the validity of the study because the total sample was examined, and the random selection of the participants ensured that the results were representative of the institutionalized elderly of this city. The comparison of the findings of this study with those of other epidemiological studies is difficult because of the variations of the methodology and diagnosis criteria among the studies. However, the diversity and frequency of the variations of normal oral mucosa and oral mucosal lesions were consistent with the findings of several studies. ${ }^{1,6-9,16-17}$ 
Most of the individuals presented with one or more oral mucosal alterations. This percentage is larger than that observed in the elderly population living in retirement homes in Finland $(59.6 \%){ }^{7}$ However, the previous study did not describe conditions that were considerably frequent in this study, such as lingual varicosities and coated tongue. Oral mucosal lesions were observed in $45 \%$ of the institutionalized elderly in Denmark; however, nonpathologic mucosal changes of the tongue were not included in the evaluation. ${ }^{6}$ In Brazil, oral mucosal alterations were observed in $60 \%$ of the institutionalized elderly population from a single institution ${ }^{8}$ using similar diagnostic criteria. In another Brazilian study, $13.49 \%$ of the elderly in the city of Goiânia presented with oral mucosal lesions, but the types of disorders were not described. ${ }^{9}$ This variability among studies can likely be explained by the different diagnostic criteria adopted.

More than half of the oral mucosal alterations observed were variations of the normal oral mucosa, which are benign and without a need for assistance. Similar to previous studies, sublingual varicosities were the most frequently observed alteration; $;^{18,19}$ they are acquired and benign conditions, and their incidence increases with age. ${ }^{20} \mathrm{~A}$ considerable prevalence of coated tongues was observed and may be related to inadequate oral hygiene or represent the side effect of medications that are regularly ingested by this age group. ${ }^{21}$ Other variations of the normal oral mucosa were observed, including Fordyce's spots, piclated and geographical tongue, and excessive melanin pigmentation. These variations were previously reported in other elderly populations with similar prevalence. ${ }^{1,6-9,18,19}$

The two most common oral mucosal lesions were related to the use of removable prostheses, confirming that the clinical problems associated with denture wear also exist in Brazilian institutionalized elderly patients..$^{5,7,19,22-24}$ Removable prostheses wear was significantly associated with a higher prevalence of oral mucosal lesions, even within a single group of elderly patients with lesions of diverse etiology. In a study of the non-institutionalized elderly in China, denture wearers had a higher prevalence of oral mucosal lesions $(40 \%)$ than non-wearers $(32 \%){ }^{19}$
In other studies, elderly denture wearers had higher chances of having a lesion (odds ratio $=3.57$ ) than those who did not wear dentures. ${ }^{23,24}$ It has been concluded that age alone has a minimal influence on the occurrence of oral mucosal lesions. ${ }^{24}$ In the population evaluated in the present study, such observations are important because approximately half of the elderly wore removable prostheses. In addition, a larger portion of the elderly had used their dentures for a period of 21 years or more. ${ }^{14}$ Some authors suggest that the length of denture wear increases with age and that the elderly are reluctant to restore or replace old dentures; however, such practices can cause oral lesions..$^{25}$

Denture stomatitis was the most frequent mucosal lesion and is a clinical diagnosis of an inflammatory lesion of the oral mucosa associated with removable dentures that is believed to be related to Candida infection. ${ }^{5,22}$ Poor hygiene in the use of the prostheses is a well-established risk factor for denture stomatitis. $^{22,26}$ The prevalence of this alteration was consistent with, ${ }^{22,27}$ lower $^{5,7}$ and higher ${ }^{6,8}$ than what has been observed in the institutionalized elderly by others. These variations can be explained by different standards of hygiene and removable prostheses. In this population, there was poor denture hygiene, with $57 \%$ of the elderly having plaque on at least one of the surfaces of the prostheses. ${ }^{28}$ There is conflicting evidence as to whether denture wear at night increases the susceptibility to denture stomatitis. Because cessation of denture wear for two weeks results in a spontaneous healing of the mucosa, it is likely that constant wear of the denture predisposes subjects to both infection and mechanical irritation of the palate. ${ }^{22}$

The second most commonly observed denturerelated lesion was denture hyperplasia. Two types of hyperplasia due to denture irritation have been recognized: one variety is associated with overextended flanges and another is associated with suction chambers. To our knowledge, the previous studies did not distinguish the types of hyperplasia. The lack of records on hyperplasia due to the suction chamber in previous studies could indicate the absence of such a condition in the populations studied. In the current study, fibrous hyperplasia with overextended flanges 
was noted in $12.8 \%$ and hyperplasia due to the suction chamber in $3.3 \%$ of the individuals. Similar frequencies of fibrous hyperplasia have been found in denture wearers in Brazil. ${ }^{8}$ Other studies have revealed highly variable results, with a prevalence of fibrous hyperplasia ranging from $9 \%$ to $16.7 \%$ of the populations of denture wearers. ${ }^{6,29,30}$ Over time, the hyperplasia due to the suction chamber should disappear because the placement of such a chamber in the maxillary denture is no longer appropriate for improving its retention. Many elderly also had traumatic ulcers due to the use of removable prostheses.

The results of this study suggest that in addition to being used with poor hygienic standards, the dentures of the elderly also have altered integrity and instability that can cause trauma and oral mucosal lesions. This relationship has been previously reported. ${ }^{30}$ The quality of the prostheses was not evaluated in this study, but the results point to a reduction in the oral health of these individuals; their oral mucosal lesions may have an impact on their systemic health and quality of life.

Although pre-malignant lesions were not a common finding in this study, eleven of the elderly had leukoplakia, indicating the necessity of periodic oral examinations for the detection of precancerous and cancerous lesions. Jorge et al. (1991) found a similar prevalence $(3.0 \%)$ in Brazil. The observed prevalence of leukoplakia was slightly higher than the reported findings in the District of Columbia (USA) $(2 \%)$ and in Denmark (2.5\%), and it was lower than the prevalence of $4.8 \%$ reported in Thailand. ${ }^{5,6,18}$

The most common oral mucosal alterations ob-

\section{References}

1. Freitas JB, Gomez RS, Abreu MHNG, Ferreira e Ferreira, E. Relationship between the use of full dentures and mucosal alterations among elderly Brazilians. J Oral Rehabil. 2008 May;35(5):370-4.

2. Wolff A, Ship JA, Tylenda CA, Fox PC, Baum BJ. Oral mucosal appearance is unchanged in health, different-aged persons. Oral Surg Oral Med Oral Pathol. 1991 May;71(5):569-72.

3. Pucca Jr. GA, Costa JFR, Chagas LD, Silvestre RM. Oral Health Policies in Brazil. Braz Oral Res. 2009 June;23 Suppl 1:9-16 served in this study were benign. Of particular significance were the lesions that were denture-induced and that could be easily avoided. Lesions that have a potential for malignant transformation are important, and their early recognition and adequate treatment have frequently been stressed. The high level of prevalence of oral mucosal lesions is one of the reasons why systematic oral examination of the institutionalized elderly is of considerable importance and ought to be carried out regularly by a dentist.

\section{Conclusions}

The prevalence of mucosal alterations was very high among the institutionalized Brazilian elderly and was associated with denture wear.

The most prevalent oral mucosal alterations not related to the wearing of a removable prostheses were sublingual varicosities and a coated tongue.

The most frequent oral mucosal lesions were denture-induced and included denture stomatitis and denture hyperplasia.

\section{Acknowledgements}

This study was supported by the CNPq and the Brazilian Ministry of Health (403244/2004-8). The authors would like to thank the assistance rendered by the Office of the Public Prosecutor for individuals with physical deficiency and of the elderly. RC Ferreira is supported by the Minas Gerais Research Foundation (Fundação de Amparo à Pesquisa do Estado de Minas Gerais) (grant for Research and Technological Development Incentive Grant).

4. Axéll T. A prevalence study of oral mucosal lesions in an adult Swedish population. Odontol Revy Suppl. 1976;36:1-103.

5. MacEntee MT, Silver JG, Gibson G, Weiss R. Oral health in a long-term care institution equipped with a dental service. Community Dent Oral Epidemiol. 1985 Oct;13(3):260-3.

6. Vigild M. Oral mucosal lesions among institutionalized elderly in Denmark. Community Dent Oral Epidemiol. 1987 Dec;15(6):309-13.

7. Ekelund R. Oral mucosal disorders in institutionalized elderly people. Age Ageing. 1988 May;17(3):193-8. 
8. Jorge J Jr, Almeida OP, Bozzo L, Scully C, Graner E. Oral mucosal health and disease in institutionalized elderly in Brazil. Community Dent Oral Epidemiol. 1991 Jun;19(3):173-5.

9. Reis SCGB, Higino MASP, Melo HMD, Freire MCM. Condição de saúde bucal de idosos institucionalizados em Goiânia-GO, 2003. Rev Bras Epidemiol. 2005 Mar;8(1):67-73.

10. World Health Organization. Oral health surveys: basic methods. Geneva: World Health Organization; 1997. 93 p.

11. Kramer IR, Pindborg JJ, Bezroukov V, Infirri JS. Guide to epidemiology and diagnosis of oral mucosal diseases and conditions. World Health Organization. Community Dent Oral Epidemiol. 1980 Feb;80(1):1-26.

12. Axéll T, Holmstrup P, Kramer IRH, Pindborg JJ, Shear M. International seminar on oral leukoplakia and associated lesions related to tobacco habits. Community Dent Oral Epidemiol. 1984 Jun;12(3):145-54.

13. Langlais RP, Miller CS. Color atlas of common oral diseases. Philadelphia: Lea and Febiger; 1992. 288 p.

14. Ferreira RC, Magalhães CS, Moreira AN. Tooth loss, denture wearing and associated factors among an elderly institutionalized Brazilian population. Gerodontology. 2008 Sep;25(3):168-78.

15. Instituto Brasileiro de Geografia e Estatística [Internet]. Perfil dos idosos responsáveis pelos domicílios no Brasil. [updated 2008 May 16; cited 2008 Jul 9]. Available from: http://www. ibge.gov.br/home/estatistica/populacao/perfilidoso/default. shtm? $=7$

16. Cebeci AR, Gulsahi A, Kamburoglu K, Orhan BK, Oztas B. Prevalence and distribution of oral mucosal lesions in an adult Turkish population. Med Oral Patol Oral Cir Bucal. 2009 Jun;14(6):E272-7

17. Muncu G, Cimilli H, Sur H, Hayran O, Atalay T. Prevalence and distribution of oral lesions: a cross-sectional study in Turkey. Oral Dis. 2005 Mar;11(2):81-7.

18. Jainkittivong A, Aneksuk V, Langlais RP. Oral mucosal conditions in elderly dental patients. Oral Dis. 2002 Jul;8(4):21823.
19. Corbet EF, Holmgren CJ, Philipsen HP. Oral mucosal lesions in 65-74-year-old Hong Kong Chinese. Community Dent Oral Epidemiol. 1994 Oct;22(5 Pt 2):392-5.

20. Ettinger RL, Manderson RD. A clinical study of sublingual varices. Oral Surg Oral Med Oral Pathol. 1974 Oct;38(4):5405.

21. Smith RG, Burtner AP. Oral side-effects of the most frequently prescribed drugs. Spec Care Dentist. 1994 May-Jun;14(3):96102.

22. Budtz-Jorgensen E. Oral mucosal lesions associated with the wearing of removable dentures. J Oral Pathol. 1981 Apr;10(2):65-80.

23. MacEntee MI, Glick N, Stolar E. Age, gender, dentures and oral mucosal disorders. Oral Dis. 1998 Mar;4(1):32-6.

24. Shulman JD, Beach MM, Rivera-Hidalgo F. The prevalence of oral mucosal lesions in U. S. adults: data from the Third National Health and Nutrition Examination Survey, 19881994. J Am Dent Assoc. 2004 Sep;135(9):1279-86.

25. Silva SRC, Valsecki Jr A. Avaliação das condições de saúde bucal dos idosos em um município brasileiro. Rev Panam Salud Publica. 2000 Oct;8(4):268-71.

26. Pires FR, Santos EB, Bonan PR, Almeida OP, Lopes MA. Denture stomatitis and salivary Candida in Brazilian edentulous patients. J Oral Rehabil. 2002 Nov;29(11):115-9.

27. Hoad-Reddick G. Oral pathology and prostheses - are they related? Investigations in an elderly population. J Oral Rehabil. 1989 Jan;16(1):75-87.

28. Ferreira RC, Magalhães CS, Rocha ES, Schwambach CW, Moreira AN. [Oral health among institutionalized elderly in Belo Horizonte, Minas Gerais State, Brazil]. Cad Saude Publica. 2009 Nov;25(11):2375-85. Portuguese.

29. Moskona D, Kaplan I. Oral lesions in elderly denture wearers. Clin Prev Dent. 1992 Sep-Oct;14(5):11-4.

30. Coelho CMP, Sousa YTCS, Daré AMZ. Denture-related oral mucosal lesions in a Brazilian school of dentistry. J Oral Rehabil. 2004 Feb;31(2):135-9. 